\title{
Investigating Decoupage and Cinematic Special-Effects in Ferdowsi's Shahnameh
}

\author{
Fatemeh Nezhad Nili ${ }^{1}$ \\ ${ }^{1}$ Master student of Persian Language and Literature, Islamic Azad University, Shoushtar, Iran \\ Correspondence: Fatemeh Nezhad Nili, Master student of Persian Language and Literature, Islamic Azad \\ University, Shoushtar, Iran. E-mail: esfehani.mohamad3@gmail.com
}

Received: September 26, 2016

Accepted: October 18, $2016 \quad$ Online Published: October 28, 2016

doi: $10.5539 /$ mas.v $11 \mathrm{n} 2 \mathrm{p} 50$

URL: http://dx.doi.org/10.5539/mas.v11n2p50

\begin{abstract}
Decoupage or cinematic segmentation is a step by step map used by filmmaker to produce a film or television show, and cinematic special effect is reconstruction and re-creation of unrealistic or impossible scenes during production process. Shahnameh Ferdowsi, due to its attractive, deep and imaginative stories, enjoys a high capacity to be exploited in the field of movies and cinematic productions. The author aims to define principles and basic concepts of decoupage and special effects as well as to extract famous stories on each of the mythological, heroic and historical sections of the Shahnameh and to adapt the poems to cinematic segmentations. The author also aims to investigate each hemistich or line as a visual shot, and battles descriptions and marvels illustrated in epic and heroic works as special effects which are capable of being reconstructed in the world of movies. Analysis of mentioned stories and adapting Ferdowsi's imageries to the scenes defined in the modern scripts, has flaunted inherent ability of the Shahnameh to regenerate and adapt itself to the present time due to its creative and illustrator poet, and represents Ferdowsi as a filmmaker with a cinematic mind. At the end, the story will be analyzed and decoupaged and turns into a full screenplay, without any interferes and just based on Ferdowsi poems to become a work of art in various visual formats such as movies, TV shows, animations, computer games, etc. At the same time, it accounts for both aspects of form and content in a prominent work.
\end{abstract}

Keywords: shahnameh, decoupage, special effects, view, camera

\section{Preface}

There is no doubt that Ferdowsi's Shahnameh, due to being a historical and mythological letter of a nation with a long lasting culture, enjoys extensive capacity to be investigated in various areas of society. One of the functional and efficient areas which can be a vehicle to know and introduce Iranian literature, especially precious masterpiece of Ferdowsi, i.e. Shahnameh, to other nations are performing arts and movies. Undoubtedly, one of the fundamental aspects of today's world is media, with its ability to reconstruct and re-create concepts, thoughts and feelings of human being and the cosmos, and of course directing, leading and even deviating human's conscious and subconscious through creative visual, theatrical and artistic ways. So, highly educated community has realized that one of the most effective Cultural-Artistic ties which lead to cultural survival and consequently national and political power among other nations is the tie between literature and art or literature and movies. Analyzing and criticizing theatrical aspects of ancient literature, especially epic literature, is limited in Iran and simply includes basics definitions and providing instances to clarify the definitions in general, and its applicable manifestation has been in illustrating children's books. So that, no fine work is produced in the field of movies and animation, not only on a global scale but also on a national scale, and what have been done so far are works produced mostly by non-Iranian filmmakers in the early years of cinema emergence with topics related to most well-known stories of Shahnameh includig Rostam and Sohrab, Siavash, Bijan and Manijeh, Rostam and Esfandiar and Kaveh ye Ahangar. We have tried to adapt the imagery presented in three dimensions of the Shahnameh, i.e. mythical, heroical and historical, with new and attractive methods used for making professional films, because Shahnameh has such a great capability in its essence. The ultimate goal of the research is to answer this question is: whether event descriptions provided in the stories of Shahnameh, particularly intended story, enjoy of visual appeals and have the capability to be converted into top movies? 


\section{Cinema: The Impact and Necessity}

Cinema is one form of art and since it is fed by the culture it will be one of the strongest and most widespread forms of popular culture. Cinema as well as other manifestations of science developments of twentieth century is one product of the industry. There is no consensus that when the history of cinema has started and different countries claim that that they have invented cinema. Although in most references this important phenomenon of twenty century is attributed to auguste and louis lumière, manufacturers of photographic materials of Lyon, France, or to Edison. At the same time, advent of cinema and its filming techniques are indebted to huge parallel advances regarding to negative films and original photographic devices. After Lumière brothers, Georges Méliès promoted cinema technology ... Georges Méliès also invented Trucage or cinematic tricks, namely what today we call it cinematic special effects. After Méliès, Edwin S. Porter evolved cinema fundamentally and structurally, and presented it as the phenomenon we know today. Porter is also known as pioneer of video editing techniques (Knight, 1992: 4).

"Art is a social phenomenon and cinema is the most social art. There are two methods to examine the relationships between cinema and society. One of these approaches focuses on the impact of cinema on society and is called "impact theory", and the other one reflects social issues in the movies and is called "reflection theory".... [This theory focuses on positive and negative impacts of cinematic productions on human life, and sometimes pays more attentions to the negative aspects]. On the contrary, reflection theory considers movies as documents that reflect social life and consequently one can perceive social developments and trends through them" (Safaryan, 2010).

\section{Poetry and Cinema}

Regarding the relation between cinema and poem it should be said that cinema is a visual art while poetry is a verbal art that imagery plays a key role in it. Cinema also presents an imagery picture reality; poetry tool is language, while cinema applies other tools too. Eventually, it seems obvious that poetry and cinema have image creation and imagery in common.

The method used by poets for imagery or so-called "Simulacrum" and create image with the help of figures of speech such as similes, metaphors, and other techniques of rhetoric, are the same methods used by filmmakers in Cinematic expression through editing the shots. Although the nature of image or imagery in poetry is different of cinematic image and in spite of the fact that poetic imagery is immaterial and subjective, and cinematic images are considered materialistic and objective, But in both of them, they are editing methods that create images. From this fundamental aspect, poetry and cinema are much more similar than poetry and painting. "(Zabeti Jahromy, 1999: 6-7).

\subsection{Imagery Capacity of Shahnameh}

The most important masterpiece and literary work, especially in the field of epic and religious literature of Iranian is "Shahnameh" by Hakim Abol Qasem Ferdowsi. Shahnameh is one of the most capable texts in ancient literary which can be adopted for filmmaking. But unfortunately in Iranian cinema, especially in post-revolutionary cinema, less attention is paid to it by directors, screenwriters and film producers. Shahnameh as a golden page in the workbook of Iranian identity and culture enjoys many advantages including story-telling, scene layout, characterization, dramatization of ancient tales and stories, creating romantic situations, writing rich and poetic dialogues, good rhythm, cinematic suspense, influential endings and more important integrating stories with pictures.

"Shahnameh is closer to cinema in compare to other arts; Shahnameh and cinema are inseparable, Shahnameh poems allow you to plunge in imageries and after soaking in the imageries embark on cinematic visualization".(Dehghanpour et al., 2010: 85).

\section{Decoupage}

Decoupage, segmentation or technical cutting is a French term, and one of the director's duties which includes deciding on the location of the camera at the scene, lighting type, image size, camera angle, camera movements, the number of images needed to display a location, bridging shots, each sound which is supposed to be heard on the stage (Any sound other than dialogue) and other details related to picturing the script (scenario). In fact, decoupage is the way that camera looks at the subject. Decoupage method conveys rhythm and mood of the film to the viewer.

\subsection{Special Effects}

Special effects in cinema are divided into two categories: free special effects and visual special effects 
Free Special Effects: In filmmaking industry free special effect refers to scenes that it is hard to produce them. These scenes will be acted in real and all of them will be played by stuntmen, artists, cameramen, and some experts in explosives and maquette making and will be recorded with cameras and some of them will be made after recording.

Visual Effects: Nowadays, if performing a scene, live in front of the camera, is impossible or costs a lot, visual effects will be used, such as storms, imaginary creatures, extraordinary actions of characters and heroes and such kinds of scenes. Today, visual effects will be made by special computer and graphic software.

\subsection{Some Basic Terms in Film Decoupage}

In a book titled "introductory training of Cinema" Massoud Jawaheri (2014), classifies and defines basic terms, and what follows are some of the key terms used in film decoupage process, extracted from his book:

Flash back: a segment of the film which has happened in the past and is showing now.

Cut: cut is an editing term which refers to cutting shots by assembler and according to decoupage.

Trucage: Trucage or film tricks generally refer to special effects.

Slow motion: Movements on the screen appearing slower than they would in actual life; Slow motion gives people a glorious and dignified motion and focuses on details. This will be done during editing in digital imaging.

Fast motion: Movements on the screen appearing more rapid than they would in actual life.

Dolly in: Moving forward and getting closer to the subject on dolly.

Dolly back: moving backward and get away from subject on dolly.

Dolly: Dolly is a crane that cameraman mounts on it and gets close or becomes far from subject depending on decoupage and moves along with subject of follows the subject and action scenes will be captured smoothly.

Dissolve: in this method of making a transition, one shot disappear gradually and the next shop will appear gradually.

Parallel event or Editing: editing or displaying two simultaneous events that happen in two different places in the film alternately. This kind of editing will be used mainly to increase excitement of the film, especially in the scenes where the hero has limited time.

Angle: A Camera can have three different angles toward a subject. If the scene be photographed from above it will be called high angle and if the scene be photographed from down it will be called low angle. Criterion for high and low angle is straight line of sight. Photographing parallel to eye horizon line is called eye level.

Zoom: This lens allows camera man to move from a wide shot to closed shot and vice versa, without needing to move camera from one place to another one.

Full Shot: A shot in which the whole body of the character will be shown. In this case, top of his head nearly touches top line and the bottom of his feet touches bottom line of the frame.

Narration: a voice coming from off screen that its narrator doesn't appear in the movie.

Dialog: conversation between two or more characters.

Monolog: opposite of dialogue where a character speaks with himself or herself.

Overhead Shot: a shot that will be filmed from above of the character or above of the location. This shot will be used to show character being imprisoned in a small place or showing his or her Confusion and chaos governing the scene.

Over the shoulder shot: a shot that is filmed from above shoulder of the character and usually includes parts of that character's shoulder or the side of the head in the shot. This shot usually will be used to show reaction of the audience in a conversation. Camera constantly shows faces of communicators in order that viewers perceive their reactions simply.

Pan Shot: a shot in which the camera turns to right or left on a horizontal axis. This move of camera will be done usually for reasons such as presenting an overview picture of the scene to the viewer, attracting the attention of the audience to a particular incident and at the same time informing him about relationship between scene components, following character or a vehicle in a panoramic landscape and providing an overview of what the character sees.

Tilt Shot: A shot in which the camera is fixed in a place and moves up and down vertically on a vertical axis. 
Such a shot can represent point of view of the character who glances a place up to down or vice versa.

Tight Shot: A shot in which characters are enclosed in frame space and little of outer space is observable. Such a shot reduces the distance between viewers and characters and creates a feeling of identification.

Traveling Shot: a shot in which the camera is mounted on a wheeled platform or is pushed on rails and follows the story or carries the viewer with it.

Follow Shot: A shot in which it seems that the camera is chasing the subject. Recording such a motion is only possible with the help of Traveling, where camera chases the subject truly, or with the help of zoom lenses, where the camera is fixed.

Crane Shot: A shot filmed from top of a crane and usually with camera movement. In this kind of shot it is possible to follow character while he or she is going upstairs, or can accompany a character to a long distance, move around above a crowd and focus on a special person, move up or move down.

Bird's - Eye View: A shot in which camera films form high above. Such a shot will be usually possible with the help of a crane of Helicopter. A shot from such angle and distance doesn't focus on a certain character or place and only provides an overview and general information for spectators.

Extreme Long Shot: A shot photographed from a great distance and provides a general view of the location. Such a shot will be used mostly as establishing shot.

Extreme Low-Angle Shot: A shot taken from below a subject, where it seems that character has leant on camera. Such kind of shots will be used mostly to show tall and terrific buildings.

Extreme High-Angle Shot: A shot taken from above a subject (vertical) that will be photographed with crane, tower or helicopter. In these kinds of shots characters are not eminent and only a general view of the scene will be provided.

Extreme Close-Up: A shot taken from a very close distance of the subject, so that only some parts of the subjects is available or some parts of the subject seems too large. If such a shot be taken from a character, only shows some parts of his or her face, such as the eyes or the mouth.

Interior / Exterior shot: A shot filmed in a closed/open space and is one of the words used as a clue on top of each scene of the script, such as interior/exterior, apartment, day.

Close Up: A shot in which it seems that the camera has got too close to the subject. In this kind of the shot, the face of the subject or a large shot of an object covers the whole frame. This shot is effective for communicating feelings, reactions and the mood of the character to the viewer and creates emotional contacts between viewer and character, and impels the viewer to focus only on the character and not on other things.

Medium Long Shot: A shot between long shot and medium shot. These kinds of the shot are not wide as much as long shots, but yet show the scene in full.

Long Shot: A shot that shows the subject from a considerable distance. In this case, besides subject other characters and part of the location that the subject is located in are observable. This shot has a general view of the subject and shows position of the subject in the scene. In fact, long shot, in compare to close and medium shot, provides more information about the relationship between subject and his or her environment. This kind of shot will be used mostly at the beginning of the sequences, especially opening sequences, as well as final sequences of the movies.

Head-On , Tail-Away Shot: A shot of the things that move straight toward camera and get close so much that cover all the frame and gradually in the opposite direction gets away from the camera, till once again it reaches to a focal distance of the camera. This technique will be used mostly to show time passing.

Hand-Held Shot: A shot filmed by a portable and lightweight camera or sometimes with the help of a strap attached to the body, which allows a cameraman to move. These kinds of the shots are mostly used in documentary movies and TV news reports.

High Angle Shot: A shot filmed from above of a subject and toward down. In this case, the camera looks down toward the subject. This kind of shot changes the height and appearance of the characters and slows their motions, therefore indicates related character vulnerable. For example, a high angle shot from a character wandering in the desert.

Low-Angle Shot: A shot filmed from below eyeline, creating a sense of "looking up to" whatever is photographed. Unlike high angle shots, this kind of shot cause that the subject seems dominant, huge and even threatening. In these kinds of shots it will be mostly tried to delete the background or minimize it as much as 
possible and show the character on sky or ceiling surface. Also, the motion of the characters photographed by this kind of shot seems rapid and viewer feels is confronted with a danger.

Arc Shot: A shot in which the camera moves in a circle or semi circle around subject. This shot can be used to create a dizzying state.

Medium Shot: A shot between long and close shots that shows characters from their ankle of knee up, or shows their stature when they are seated. This shot is mostly used to show relationships between two or more characters, and at the same time providing sufficient information to involve the viewer.

\section{Mythological Part: The Kingdom of Jamshid, Zahhak, and Feraidun's Mutiny}

The selected literature is derived from Daftar Khosrowan (a selection of Shahnameh) compiled by Sajjad Aidenlou and based on the major events in Shahnameh's poetical stories.

123-As the King's life was about to terminate

His advice valuable, his words precious

The narrator's voice is synchronized on the images (narration)

The narrator can be Ferdowsi or the compiler of Nameh Baastaan (the original name of Shahnameh referred to by Ferdowsi, and it should be noted that he never mentioned the term "Shahnameh" for naming his masterpiece) in the literature dating back to the past (the compiler of Naameh Baastaan /as a Zandian hero of the story).

As the King's life was about to terminate

High angle shot, the camera angle from above, while Tahmuras's death is imminent.

His advice valuable, his words precious

Dally back from the courtiers that are assembled around him.

124-Jamshid, the mighty son of Tahmuras,

Full of his father's maxims, girt himself

Medium close shot of Jamshid with a sorrowful appearance yet so determined.

125-Mine is the Grace," he said, "I am both king

And archimage, I will restrain ill-doers

Close-up of Jamshid, and his dialogue: "Mine is the Grace", he said, "I am both king

And archimage, I will restrain ill-doers

126-For every craft; it took him fifty years.

Traveling shot of the different classes of the mass and coming out of some people among these masses concurrent with camera's movement.

It took him fifty years.

Low-angle shot of those who are the master of the classes mentioned in the next lines.

127-To be employed in sacred offices,

He separated it from other folk

Tilt shot of a group of people back to camera which are worshipping with a position toward a specified location. 128-And made its place of service on the mountains

That God might be adored in quietude.

Medium long shot of the mountains and the worshippers.

129-Arrayed for battle on the other hand

Pull-back shot of a group which ride on the horses with a position in front of the camera.

Were those who formed the military caste,

Low angle shot from a flag which is wavering or has a special color or emblem.

130-They were the lion-men inured to war -

Medium shot from the warriors rushing from one frame to another frame.

The Lights of armies and of provinces-

Low angle shot from the warriors and commanders standing over the height so proudly. 
135-Are given much to thought. Jamshid thus spent

Another fifty years and did much good,

Low angle shot of Jamshid which has an emblem on his chest or delivers a scroll to the master of each of the castes.

131- For each man learnt his place and others' too.

He bade the foul divs temper earth with water

Medium close shot of the masters which bow to Jamshid back to the camera and in front of Jamshid, and then go out of the cadre (frame) in the same manner.

Emergence of Zahhak

175- Ordered the div as such a companion

To kiss his shoulders.

Medium close shot of the div who is standing behind Zahhak with naked shoulders, and gently and flirtingly strokes his head and face over Zahhak's shoulders and neck.

176-The div kissed and vanished

All the world's eyes were fixed and perplexed.

The close-up of the div's lips which kisses Zahhak's shoulders, and cut to high angle shot of the div (special effects), and the earth's mouth opening, and the div who vanishes into the ground with a swirl of smoke and fire.

The warlock's shoulders grew two snakes

Special effects, arc shot from Zahhak which swirls and shouts.

A black snake with an open mouth growing from a shoulder and another black snake growing from another shoulder.

Became sorrowful and looked for a device to heal

Medium shot of Zahhak who is standing at the center of the images of the physicians (who are attempting to heal him), and Zahhak and snakes are impatient and restless.

177-Div searched for a heal

Approaching Zahhak to attain wisdom

Special effects, medium shot and high angle shots of the div which is transformed into a healer, and coming toward the camera among other healers in a travelling shot. Over-the-shot shot of Zahhak's shoulders, his snakes back to the camera, and the div in front of the camera.

Emergence of Faridun

216- Years passed away, calamity approached

The dragon-king, the blessed Faridun

Was born, the fashion of the world was changed.

Close-up of Faranak which is in a severe pain, and finally crying of an infant and cut to a close-up of Faridun

217- Was like the sun, as needful as the rain

To earth and fit as knowledge to the mind

218- The wise, the archmages, and astrologers

Collected round her; none had seen or heard

Of such a cow before.

219-Born with a coat all bright and peacock-hued.

Parallel cut/medium close shot of Faranak who is in a severe pain/medium close shot of the cow who is in a pain/medium close shot of Faranak who its pain is ultimately subsided following the birth of the infant/ medium close shot of the cow and Barmayeh's voice and cut to the medium close shot of Faridun/medium close shot of the beautiful cow of Barmayeh.

220- Abtin, of royal race, discerning mind, wise, brave,

Faridun's father, was in deep sorrow

Medium close shot of Abtin which smells and kisses Faridum, the voice of knocking on the door, and cut to 
worried medium close shot of Abtin.

221-Seized him and bore him, like a cheetah bound,

Hand-over shot of Abtin hand-tied moving along the frame, and the camera follows them.

Before the Shah, who had him put to death.

Low angle shot of Zahhak who raises a sword and brings it down, and Abtin's blood splashes over Zahhak's face and snakes.

\section{Fariduns' Riot and Zahhak's Collapse}

269- The warriors' heads

Reeled while their swift steeds struggled with the tide,

And with their necks emerging seemed to be

The phantom cohort of a dream.

Relatively long shot of Fraidun in the front of the army which approaching the camera, and water splashes surrounding due to their crossing from Arwand River.

273- When they approached the city that they sought,

And Faridun beheld it a mile off,

He saw a pile whose building towered o'er Saturn,

274-The hero recognized that seat of power

And springlike beauty as the Dragon's dwelling,

Medium and high angle shot of Faridun who stands a location and looks out of the frame, and cut to long shot and high angle shot of Zahhak's tower and Fraidun and his army while there are back to the camera.

295-His feet no sooner rested on the ground

Than Faridun rushed on him like the wind

Low angle shot of Zahhak who descends from the stairs (the continued image of the previous half-line), and cut to Fraidun's travelling shot which comes in and out of the frame instantly.

296- He rushed with ox-head mace to fight Zahhak,

Smote him upon the head, stripped off his skin,

Special effect, low angle shot from Zahhak and Faridun who entering the frame, cut to low angle shot of Faridun which brings ox-head mace over his head and is about to hit Zahhak, cut to close-up of Zahhak and snakes which look above, and cut to medium shot of Zahhak and snakes where the mace enters the frame. In this state, the audience can see slow motion of the scene where Fraidun hits Zahhaks' head with mace.

297- "Strike not," cried blest Surush, who hurried thither,

"His time hath not yet come, but bind him vanquished

Special effects, low angle shot from a light that descends from top to bottom, and emerges as a blest Surush, and cut to the medium close shot of Faridun which the angel whispers in his ear that: "His time hath not yet come"

303- Dragged him before the crowd in shame and anguish

Toward Mount Damavand.

Long shot of Damavand, cut to the low angle shot of Damavand, and Zahhak back to camera.

304- Bound by the hands upon a crag, that so

His anguish might endure, his heart's blood trickled to the ground.

Special effects, reversed and low angle shot from hand-tied Zahhak who is suspended from the mountain and blood flows from his mouth, and the snakes move on his body. Cut to dally back shot and camera's distancing from Zahhak, camera's crane from Damavand to the sky and Zahhak which is gradually vanished in the middle of the frame, and the image becomes increasingly misty and vague.

\section{Pahlavani (heroic) Part}

1236: Nine months passed and a moon-like babe was born;

Thou wouldst have said: "'Tis elephantine Rustam,"

Fast motions of the alterations in night and day based on the passage of time, cut to the medium close shot of Tahmineh's painful face, and an infant which is delivered to him. 
1238: And since the babe smiled and was bright of blee

Tahmina gave to him the name Suhrab.

Medium close shot of smiling Sohrab embraced by Tahmina, and Tahmina's monologue: Sohrab

1239-1241: He looked a year old in a month, his chest

Was like his sire's, at three he exercised

In arms, at five he had a lion-heart,

At ten none dared encounter him in fight.

Three full view of Sohrab in three, five, and ten years old which exercises Chogan (a type of polo-stick, an ancient game) at age three, practices shooting at five, and can fight or wrestle when he is ten years old, and in all of the plan is superior to his peers.

1471: Flint rocks become like wax. The two began

To wrestle, holding by their leathern belts.

Medium close shot of both of them when getting off from the horses, and cut to low angle shots of those two who start to fight (wrestling).

1472: As for Suhrab thou wouldst have said: "High heaven

Hath hampered him," while Rustam reaching clutched

1473: That warrior-leopard by the head and neck,

Bent down the body of the gallant youth

Medium close shot of Rostam and Sohrab. Sohrab is at the bottom and Rostam is above, and the face of both appears distressed.

1474: But when he seized the belt and would unhorse

Suhrab, the young man's waist felt not the tug,

And Rustam's hand was foiled

1475: Then, knowing that Suhrab would not stay under,

Drew lightly from his waist his trenchant sword

High angle shot of Sohrab which falls to the ground and cut to low angle shot of Rostam.

1476: Drew lightly from his waist his trenchant sword

Arid gashed the bosom of his gallant son.

Slow motion and low angle shot of Rostam while drawing his sword, cut to the slow and closed motion shot of cutting Sohrab's bosom and blood flow.

1477: Naught reeked he then

Of good or ill. "I am alone to blame,"

He said to Rustam: "Fate gave thee my key.

Medium close shot of Sohrab's face which sighs so desperately...

1484: The world grew dark before his eyes, he quitted

The battlefield and coming to Hajir

The shot of Rostam's and cut to his arc shot...

1524-While all went blind with grief he made a charnel

Shaped like a horse's hoof.

High angle shot of the charnel which is Sohrab's grave, and dally back from the charnel to Rostam, and many people who have gathered around him, and gradual dissolve of the image to darkness and the voice of the narrator (Ferdowsi)

1525- The tale of how the paladin had slain

His son went everywhere and all the world

Was full of grief, while Rustam sorrowed long,

\section{Historical Part}

Yazdgerd's Kingdom Fate

8726- In a night at the Aniran of Khordad 
The miller traced the King

Medium close shot of the miller's desperate and frightened face, and cut to the long shot of him which fades into the background in darkness.

8727- The king's flank was haggled

The kings' sigh, caught in pain, lesion on his body

Low angle shot of the miller in a half-dark scene where he draws the sword and brings it down, and cut to the high shot angle of Yazdgerd cut in the flank by a sword, and Yazdgerd in pain and sigh and wide eyes stares into the camera (miller)...

8730- The king's body thrown into the pond

In a dark night, in a dark scene

Medium shot of the pond which Yazdgerd's body is thrown into it, and at the background of the scene a monk back to the camera looks at the event.

8731- Of pious mourners in the night

One approached the brink of the pond

Over-the-shoulder and backward shot of the monk which approaching the brink of the pond.

8732- His body naked on the water

Washed by the tide, brought in an instant

Medium shot of Yazdgerd's nude body on the water, cut to the medium shot of a person who looks at it desperately and frightfully, and cut to his travelling shot while running facing the camera...

8738- The king's body was brought of the pond

Youth and old all in cry, all in sigh

High angle shot of the monk which takes Yazdgerd's body out of the pond, and cut to the long shot of the mourning mass beside the pond.

8739- A vault constructed into the orchard

Head raised into the clouds, full of pride

High angle shot of Yazdgerd's adorned body in the coffin, and its tilt shot from Yazdgerd to a elevated vault in the heart of the mountains.

\section{Conclusion}

The current article investigated a part of the literature of the three main sections of Shanameh as decoupage text or raw script of a screenwriter. Regardless of some lines of Shahnameh which revolves around proposed ideas, words, advice, wisdom, and long dialogues between characters, the visual literature of Shahnameh which describes events and pahlavaniha (heroic incidents) can be fractionated into various cinematic screen shots, and Shahnameh's exaggerations and defamilaristic devices are fully consistent with the issue of the construction of cinematic special effects, and the result is generalizable to all Shahnameh's lines and stories in its three major parts including mythological, heroic and historical one In addition, in every line of Shahnameh which is composed based on a narrated image, and is free from hakami or dialogic literature, it is possible to decoupage one to four shots per each line.

Table 1. Ratio of Shahnameh's literature to the decoupage shots

\begin{tabular}{ll}
\hline Line & Shot \\
\hline 1 & $1-4$ \\
The Relevant Literature in the Current Article 50 & $50-200$ \\
\hline
\end{tabular}

Today, thanks to the phenomenon of computer, and sophisticated accurate computer software, many interesting and impressing effects are formed on computer screen. In the mythological part of Shahnameh, due to the existence of myths and transformed reality of things and phenomena, the readers are faced with devils (divan), dragons or fabulous events such as growth of snake on the shoulders of Zahhak, Siavash passing through the fire, 
and the like, which plausible and external representation of such images is possible through field computer and special effects.

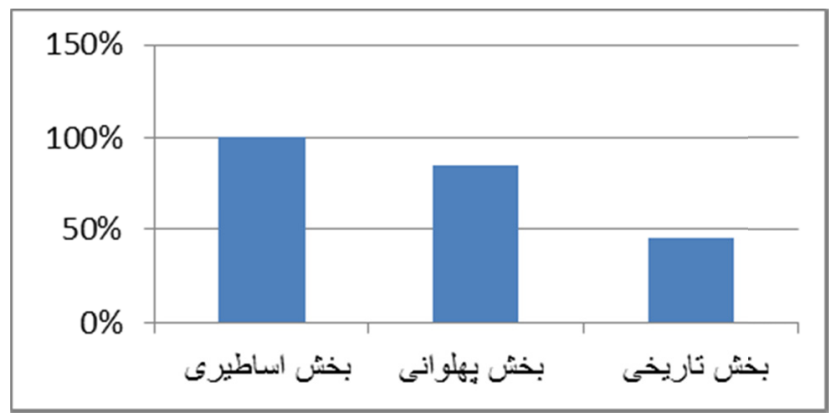

Figure 1. The ratio of special effects to the Shahnameh Mythological Part, Pahlavani (heroic) Part, Historical Part

\section{References}

Arnheim, R. (1981). Film as art. (F. M. Moqadam Trans. ). Tehran: Amir Kabir

Aidenlou, S. (2011). Daftar-e-Khosrowan. Tehran: Sokhan

Starikov, A. (1977). Ferdowsi \& Shahnameh. (R. Azarakhshi Trans.). Tehran: Pocket Books Organization.

Es'haqpour, Y. (1994). Cinema. (B. Parham Trans.). Tehran: Forouzan.

Dadli, A. (1989). Basic Theories on Cinema. (M. Madani Trans.). Tehran: Rahrovan Pouyesh Publications.

Bazan, A. (2007). What is cinema? (M. Shahba Trans.) Tehran: Hormos Publications (3rd Ed.).

Buckland, W. (2013). An introduction to the basics of cinema and film criticism. (P. Tehranian Trans. by). Tehran: Mo'ein Publications.

Bayanlou, H., \& Samimi, T. K. (2011). Paleontology in cinema. Tehran: Pajouheh Publications.

Jeniks, W. (2010). Literature of film, status of cinema in humanities. (M. T. Ahmadian \& S. Hakimian Trans.). Tehran: Soroush Publications.

Hanif, M. (2010). Dramatic potentials of Shahnameh. Tehran: Soroush Publications.

Rahnama, F. (2002). Realism in film; under the supervision of Faraideh Rahnama. Tehran: Norouz Cultural Artistic Institution

Zabeti, J. A. (1997). Cinema and structure of poetical images in Shahnameh. Tehran: Afra.

Ferdowsi, A. (2005). Shahnameh. In Saeid Hamidian (Ed.), based on Moscow Published Version. Tehran: Ghatreh Publishing Center.

Ferdowsi, A. (2007). Shahnameh. Tehran; Hormos Publications (3rd Ed.).

Kispier, A. (2009). Understanding Film; Bahman Taheri. Tehran: Cheshmeh Publications.

Gesner, R. (1989). Motion picture: a guide to cinema. (A. Shari'atzadeh Trans.). Tehran: Soroush Publications.

Loteh, J. (2007). An introduction to narration in cinema and literature. (O. Nikfarjam Trans.) Tehran: Minooye Kherad Publications.

Mobasheri, K. (1998). Film decoupage in film and TV programs. Tehran: Nai Publications.

Mohammadi, M. (2011). Iran's Contemporary Cinema. Tehran: Iranian Community

Knight, A. (1992). History of Cinema. (N. Darya Bandari Trans.) Tehran: Pocket Book Company.

Wotila, S. (2011). Myth and Cinema. (M. Gozarabady Trans.) Tehran: Hormos Publications (2nd Ed.).

Heward, S. (2012). Key concepts in cinema studies; translated by Fattah Mohammadi. Third Millennium (Hezareh Sovom) Publications (4th Ed.).

Spigel, A. (2000). Cinema and Literature, cinematic editing \& literary editing. (A. Horri Trans.) Farabai Film Quarterly, 10(39), pp. 141-156. 
Pahlavani, E., Kazazi, J., \& Roe'yaei, T. (2013). Shahnameh as a founder of some genres of Iranian drama; Journal of Theater; Issue 169; pp. 74-78.

Hakemi, V. E., \& Raeisim, B. M. (2005). A review of dramatic aspects in Shahnameh and Khamseh by Nezami. Journal of Humanities and Sciences University, 172-176, pp. 1-22.

Hayati, Z. (2012). A comparison of literary metaphor and cinematic metaphor with some documents on Persian poems; Journal of Literary Research, 9(38); pp. 35-58

Khodaparasti, B. (2008). Multimedia arts, multimedia myths. Journal of Art, 77, pp. 321-375

Dehghanpout, H., Kazzazi, J., \& Pourrezaeian, M. (2010). Shahnameh and its cinematic aspects, Siavash Tragedy. Journal of Dramatic and Musical Arts, 40, pp. 85-97.

Razavi, M. (2008). Cinema and Literature. Journal of Hekmat and Art, 3, pp. 34-40.

Shari'ati, M. (2001). Shahnameh is contemporary. Child and Adolescent Book of Month, 5(51), pp. 10-14.

Anasori, J. (1989). Influence of narratives and ancient literature in Cinema. Journal of Chista, 8(37), pp. 386-393.

Safoura, M. A. (2007). Iranian stories and myths in Iranian Animation. Art Book of Month, 103, pp. 103-104.

Nasibi, N. (1978). A review of Iranian cinema and actors Negin Journal, 102, pp. 51-55.

Hashemi, M. (2009). An analysis of Shahnameh in Cinema and TV. Journal of Art, 77, pp. 285-330.

Jalali, F. (2010). Shahnameh in the Cinema. Retrieved from http://www.ferdosi-toosi.blogsky.org

Javaheri, M. (2014). Introduction to Cinema 1 and 2. Retrieved from http://www.cinemodern.ir

Network of Scientific Association of Persian language and literature students (2014). Movie adaptation of the Shahnameh, the cinema and literature. Retrieved from http://www.anjomanfarsi.ir

Safarian, R. (2010) Community and Cinema. Retrieved from http://www.anthropology.ir

\section{Copyrights}

Copyright for this article is retained by the author(s), with first publication rights granted to the journal.

This is an open-access article distributed under the terms and conditions of the Creative Commons Attribution license (http://creativecommons.org/licenses/by/4.0/). 